\title{
Correction to: Partial Ownership for Outer Space Resources
}

\author{
Erwan Beauvois $^{1,3} \cdot$ Guillaume Thirion $^{2}$
}

Published online: 8 June 2020

(c) The Author(s) 2020

\section{Correction to:}

Advances in Astronautics Science and Technology https://doi.org/10.1007/s42423-019-00042-0

Due to a lapse the manuscript without revision was published.

The original article has been updated.

The original article can be found online at https://doi.org/10.1007/ s42423-019-00042-0.

Erwan Beauvois

beauvois.erwan@gmail.com

Guillaume Thirion

guillaume.thirion@isae-alumni.net

1 International Master SEEDS, Politecnico di Torino, Turin, Italy

2 International Master SEEDS, ISAE-Supaéro, Toulouse, France

3 University of Leicester, University Rd, Leicester LE1 7RH, UK 